\title{
EDITORIAL
}

\section{Oral scientific traditions}

I have just returned from the Golden Jubilee meeting of the Nutrition Society in Cambridge and, although it will be several months before this editorial appears in the Journal, I felt that I could not let the meeting to celebrate the foundation of the Society fifty years ago pass unmentioned in the Journal. In fact it is probable that the editorial may be published closer to the anniversary of the first meeting of the Society in October 1941 than the celebrations in Cambridge!

I do not wish to give a detailed report of the meeting because I am sure that many such reports will appear in 'Nutrition News and Notes', but to reflect on the value of scientific meetings and the oral traditions that have played an important part in the development of the sciences. The Jubilee meeting proved to be a classic example of how important it is to hear a researcher describe his or her own subject and researches to a gathering of fellow scientists. Some would argue that they prefer to see the work in a printed paper so that they can consider the data in detail without the constraints of having to read and remember data presented fleetingly on a, sometimes illegible, slide. There were, of course, very few such slides in evidence at the Cambridge meeting; after all, the people invited to speak were experienced performers.

It is essential to recognize the importance of the presentation itself in interesting the audience and in arguing the case for acceptance of the ideas presented. An air of theatricality comes through from the most effective presenters; not necessarily in a flamboyant style - a studied nonchalance in presenting a key piece of evidence that required great intellectual effort in the design of the experimental work and meticulous skill to obtain it is just as, if not more, effective.

I believe that one of the most important features of an oral presentation is that the speaker is presenting, if not his or her own work, a field of study to which the researchers' time and effort have been given. The area excites the researcher and has demanded commitment. Secondly, talking about the work requires a different and more colloquial style than the written paper; the use of personal pronouns is natural and the ideas for experimental designs can be seen to develop logically and do not appear from thin air, as often seems to be the case in the most formal written papers. In an oral presentation one is more likely to gain an insight into the thought processes involved in developing ideas and in learning why a particular line of investigation was followed; the more experienced a researcher the more one is likely to learn of false leads and failed experiments, because these often provided the pointers to the correct lines. In published papers the end result is known and a pathway to it is constructed and presented in the paper. In real time the correct path is not known until it has succeeded.

The importance of serendipity in the evolution of scientific understanding was clearly in evidence in Cambridge. Many times I began to wonder how those who made the really major advances - because they were curious, ingenious experimenters, careful observers, able to recognize and seize an opportunity when it became available, and often luckywould fare in today's mission-orientated environment.

The papers we heard in Cambridge explained how the scientists came to work on their subject, and the importance of personal contact with, and inspiration from, the distinguished workers who came before them was very evident; there was much talk of heroes and heroines and little of committees that identify priorities. 
Above all, the papers gave a good impression of research as it really is, intriguing, baffling at times, often frustrating, but above all a creative activity that cannot be separated from the human beings that carry it out.

This is the major benefit of attending scientific meetings, one that cannot come from reading the literature alone. All of those who were fortunate to be present were given an insight into this creative process and the inspiration to take our part in the process. Although the nutritional sciences have made great strides in the past fifty years, many of the responses of the living organism to its diet remain a mystery. Their resolution, in addition to the intellectual excitement that this brings, will make important contributions to human health and well-being.

D. A. T. SouthGate 